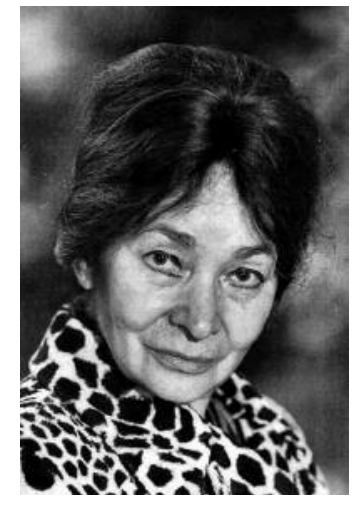

Magda Szabó nace en Hungría en 1917 y vive en Budapest en el seno de una familia burguesa y especial (su padre le hablaba en latín, según cuenta en sus memorias). Empezó a publicar después de la Segunda Guerra Mundial y fue represaliada al igual que su marido, el escritor Tibor Sziobotica, por los comunistas, aunque algunos años más tarde reanudó su obra y su proyección. En 1987 publicó La puerta, tal vez su novela más internacional, con la que ganó, entre otros, el Premio Femina.

Obra traducida al inglés: The door, The fawn, The Night of the Pig-Killing or Night of the Pigkilling, Tell Rally, Sziget-kék, An old-fashioned store.

\title{
OBITUARIO
}

Magda Szabó murió el 19 de noviembre de 2008, unos días después de terminar Nueve gatos y un perro. Intuía esa muerte, he escrito en esa magia frágil, transparente de los grises asomada en un balcón con la mirada doble; la de una niña que descubre a una escritora magnífica y la de una mujer madura que aprende a despedirse de la vida; esa que retiene el pasado con una mano y el presente con otra. Hungría tendrá el sabor de Szabó, y mi mundo hilará su memoria palabra a palabra. Mi vida con Magda, curiosamente, acaba de empezar. El final en la literatura no existe.

T. Agustín 


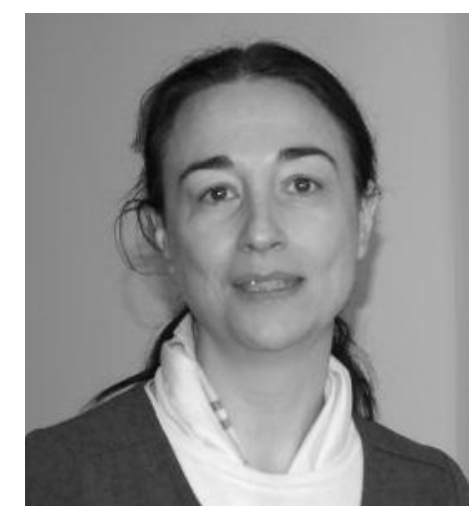

Teresa Agustín es poeta y nació en Teruel en 1962. Empezó a publicar a los veinte años en revistas como Turía y Andalán. Ha traducido, entre otros, a Marguerite Duras. Hasta la fecha ha publicado los libros Dhuoda (Asociación Cultural Ana Abarca de Bolea, 1986), Cartas para una mujer (PUZ, 1993); La tela que tiembla (Olifante, 1998); Hombre sentado en un jardin, con lirios, lilas y dos amapolas (Prames, 2004); Dos Pasillos (Huerga y Fierro, en prensa). Su obra figura en diferentes antologías: Erotemas (Ayuntamiento de Zaragoza, 1980), Poemas a viva voz (IFC, 1988), Penúltimos poetas aragoneses (DPZ, col. Veruela, 1990), Ellas tienen la palabra. Dos décadas de poesía española (Hiperión, 1997), Mujeres de carne y verso: antología poética femenina en lengua española del s. XX (La Esfera de los libros, 2001).

$\Rightarrow$ prensa@falternativas.org 


\title{
NUEVE GATOS Y UN PERRO \\ (entrevista sin preguntas). \\ LA PUERTA, DE MAGDA SZABÓ
}

\section{Teresa Agustín}

\begin{abstract}
RESUMEN
Magda Szabó nace en Hungría en 1917 y sus primeras obras ven la luz a finales de la Segunda Guerra Mundial, pero cuando los comunistas llegan al poder ella desaparece de la escena literaria hasta la década de los sesenta, en que publica poesía, novela y ensayo. Probablemente hoy es una de las autoras más destacadas y reconocidas de la literatura húngara y su obra ha sido traducida en más de cuarenta países.

La puerta, única obra publicada en España, es una historia real novelada entre dos mujeres, una escritora célebre y su criada. También es la historia de nueve gatos encerrados en una habitación y un perro, Viola, que se convierte en el catalizador de lo afectos. Es la vida de dos mujeres diferentes, con vidas diferentes, con edades diferentes, que acaban siendo indispensables la una para la otra. Es también un país, Hungría, como telón de fondo, que durante mucho tiempo también vivió encerrado en una habitación.

$\Rightarrow$ PALABRAS ClAVE: puerta, habitación, comida, Emerenc, barrio, Viola, herencia, pañuelo, escritora, puerta.
\end{abstract}

Siempre giro la llave, pero nuestro destino es el de seguir luchando en vano. Parece que a lo largo de esos años las estaciones no se sucedan, hay nieve y el paisaje se retrata en grises, como si todo ocurriera entre el otoño y el invierno, sólo por la nieve que Emerenc barre de vez en cuando; por lo demás, el color del sitio es gris, como en un eterno otoñal. Todas las vidas tienen una puerta, la llave puede existir o no, puede encontrarse cerca o lejos, tal vez llega colgada de nuestro cuello a la hora de nacer, como un regalo, o la nuestra, la que nos corresponde, la que abre, está colgada de otro cuello y pueda ser que no la merezcamos nunca, o que simple- 
mente, no la encontremos jamás. ¿Hay algo más fascinante que una puerta cerrada que lleva a una habitación propia, que contiene un secreto? Pensamos en lo que hay dentro, pero en realidad lo más fascinante es el camino que lleva a la llave, esa otra, que contiene tu propio silencio, que sin saberlo da forma a tus amnesias. Lo que se encierra en ese cuarto también está fuera, soy yo misma. Mi herencia material se hace polvo, se desvanece cuando finalmente la toco. Al final de este libro hay otra puerta.

«Nos atendió durante más de veinte años, pero en los cinco primeros se podía percibir, con la precisión de un instrumento de medición, la distancia que ella marcaba en la relación. Yo tengo un carácter abierto, me gusta hablar con la gente, incluso con desconocidos, pero Emerenc limitaba la comunicación a lo estrictamente necesario».

Es una historia real, como siempre retratada y mentida por la literatura, es la vida de alguien anónimo como tantos, que recorre un camino, topándose con unos y otros como tantas «colometas», sin ser consciente de ello. En este barrio de maravillas las cosas parecen detenidas en el tiempo y el universo transcurre entre esas calles, es casi una obra teatral intimista donde la narración se sitúa en un dilatado espacio de tiempo y donde suceden en realidad pocas cosas, pero donde se sacude todo un universo. Es la atracción entre dos mujeres, no es el retrato de un hombre y una mujer, o dos hombres, son dos mujeres: la una inculta y viva en su propio exilio interior, y la otra culta, una escritora, fascinada por la libertad cautiva de la otra. Poco a poco la vieja colometa húngara revienta el universo formal de la escritora. 
Lo cotidiano, que es lo que se retrata, llega a resultar fascinante, no es sólo la historia de una amistad, es también la relación entre dos generaciones, el desencuentro, y la relación de poderes entre una criada y su señora. Una criada que tiene una puerta cerrada, que sabe manejar la llave de la indiferencia, que no tiene horario. Tal vez es el empeño «de que las personas más cercanas manifiesten el placer de volver a verme». Un empeño que nos obsesiona, es una verdadera historia de amor; lo que parece que llega y no llega en realidad; «éramos amigas» lo que parece que sí, que ya es, pero siempre hay algo que lo trastoca y hay que volver a reconquistarlo. En el fondo se trata de sentir siempre atracción por la otra, que no acaba de ser del todo nuestra, sentir esa curiosidad, ese algo que hace que alguien siempre nos parezca que está por descubrir, que siempre nos cuenta cosas que no nos aburren, que nos mantienen alerta, aunque no tenga nuestros gustos, ni podamos hablar en el mismo registro. Alguien «que no deja entrar a nadie en su casa». Un perro se convierte en el catalizador de los afectos, él sólo reconoce a Emerenc como dueña y señora, como madre y ella actúa como tal, castiga y premia, y lo hace como sólo puede hacerlo alguien que se ha relacionado con la vida rozando su dureza, nuestra vieja.

«Emerenc sostenía que la labor intelectual no era más que simple holgazanería, casi comparable a trucos de magia barata», pensaba que la «sociedad estaba dividida en dos, los que barrían y los que ordenaban barrer», «odiaba la idea de poder y, con ella, a cualquiera que lo ejerciera». Nuestra sirvienta había sobrevivido a ese destino que cruzó todos los mapas de Hungría. Hungría, dicho «sin ningún transfondo de patriotismo sentimentalista» con una Primera Guerra Mundial en la que salió derrotada de la contienda. 
Para años después en una sucesión de proclamas republicanas y comunistas el país fuera perdiendo territorios e identidades, y luego la Segunda Guerra Mundial y un pueblo, que no era fascista terminó al lado de Hitler y finalmente, invadido por las tropas alemanas. Y luego llegaron las deportaciones de los judíos húngaros y la persecuciones. Y luego las tropas soviéticas se quedaron con el país y todo se tiñó de grises. Y Emerenc ayudaba a los judíos, refugiaba a un alemán herido o a un ruso en su alcoba secreta. Ella "prefería decidir por si sola», siempre animada por un espíritu de lo solidario, de esos que hacen sobrevivir a los pueblos. Es la matrona que hace el caldo para el vecino enfermo, es la que cocina para sus gatos, encerrados en una habitación, la que mima al perro Viola, la que manifiesta su amor haciendo comida y haciendo comer.

«Ella no aceptaba ese país». "Yo asumía el papel de Robespierre, la representación de la soberanía popular, a pesar de que a mí, personalmente, ese poder pretendía quitarme de en medio censurando mi obra literaria y obligándome a aislarme en un gueto privado, junto con mi marido ya bastante humillado hasta el punto de ver secada su vena creativa». «Acorralada de ese modo, sólo me dejaban dos opciones para borrarme del mapa: quitarme la vida o abandonar el país. Pese a todo, logré mantenerme a flote, tan fuerte era mi odio hacia mis perseguidores». Así era este país. Luego vino la revolución del 56 y entró un poco de aíre fresco, era «la barraca más alegre», o eso decían respecto a los otros países del Este.

Era el lado negativo lo que ella veía, era tal vez su dignidad lo que dejaba aflorar su visión dramática de la vida y de la historia que le había tocado vivir. Es esa visión oscura del ser humano que acaba 
sacando lo peor de uno mismo y lo mejor, pero que no predispone a la dulzura, o sólo se sabe de ella pasado el tiempo. Son los supervivientes. El retrato de alguien que no pide nunca nada, que no depende de nadie pero que es capaz de dar lo mejor de sí mismo y de proteger a los demás marcando distancias e imponiendo carácter. Lo puro, sin el edulcorante añadido de los buenos. Esa clase de gente a la que amas sin saberlo y que te enseña que «morir del todo no es tan fácil», de los que aprendes una vez abierta la puerta de una habitación que en el fondo no contiene más que polvo.

Son los nueve gatos encerrados en una habitación, que viven cautivos pero están vivos. «Si Viola y esos gatos encontraran la libertad morirían». Y mueren los nueve gatos y Viola, el perro, que muere en vida. Y termina una novela. Y yo misma, que me acercaba sin saber a la enfermedad, a la vejez, a la soledad y al desamparo. "Que yo era su hija lo supe cuando los gatos y Emerenc ya no estaban». Cuando rompimos sus puertas y la «herencia se desvaneció». Cuando la ausencia te descubre que el destino de los hombres es el de seguir luchando en vano y «yo soy ya bastante mayor para sentir vergüenza por el pasado».

Los ojos de Emerenc eran azules, los míos ya no recuerdo. 